\title{
Comparison of the predictions of two road dust emission models with the measurements of a mobile van
}

\author{
M. Kauhaniemi ${ }^{1}$, A. Stojiljkovic ${ }^{2}$, L. Pirjola ${ }^{3}$, A. Karppinen ${ }^{1}$, J. Härkönen ${ }^{1}$, K. Kupiainen ${ }^{2,4}$, L. Kangas ${ }^{1}$, \\ M. A. Aarnio ${ }^{1}$, G. Omstedt ${ }^{5}$, B. R. Denby ${ }^{6}$, and J. Kukkonen ${ }^{1}$ \\ ${ }^{1}$ Finnish Meteorological Institute, P.O. Box 503, 00101 Helsinki, Finland \\ ${ }^{2}$ Nordic Envicon Oy, Huopalahdentie 24, 00350 Helsinki, Finland \\ ${ }^{3}$ Metropolia University of Applied Sciences, Department of Technology, P.O. Box 4021, 00180 Helsinki, Finland \\ ${ }^{4}$ Finnish Environment Institute, P.O. Box 140, 00251 Helsinki, Finland \\ ${ }^{5}$ Swedish Meteorological and Hydrological Institute, 60176 Norrköping, Sweden \\ ${ }^{6}$ The Norwegian Institute for Air Research, P.O. Box 100, 2027 Kjeller, Norway
}

Correspondence to: M. Kauhaniemi (mari.kauhaniemi@fmi.fi)

Received: 26 November 2013 - Published in Atmos. Chem. Phys. Discuss.: 17 February 2014

Revised: 19 June 2014 - Accepted: 21 July 2014 - Published: 8 September 2014

\begin{abstract}
The predictions of two road dust suspension emission models were compared with the on-site mobile measurements of suspension emission factors. Such a quantitative comparison has not previously been reported in the reviewed literature. The models used were the Nordic collaboration model NORTRIP (NOn-exhaust Road TRaffic Induced Particle emissions) and the Swedish-Finnish FORE model (Forecasting Of Road dust Emissions). These models describe particulate matter generated by the wear of road surface due to traction control methods and processes that control the suspension of road dust particles into the air. An experimental measurement campaign was conducted using a mobile laboratory called SNIFFER, along two selected road segments in central Helsinki in 2007 and 2008. The suspended PM 10 concentration was measured behind the left rear tyre and the street background $\mathrm{PM}_{10}$ concentration in front of the van. Both models reproduced the measured seasonal variation of suspension emission factors fairly well during both years at both measurement sites. However, both models substantially under-predicted the measured emission values. The article illustrates the challenges in conducting road suspension measurements in densely trafficked urban conditions, and the numerous requirements for input data that are needed for accurately applying road suspension emission models.
\end{abstract}

\section{Introduction}

Fine particles primarily originate from combustion sources, whereas coarse particles are produced mechanically by construction activities, windblown suspension (WHO, 2005), and the wear of road surface and vehicle components (e.g. Kupiainen, 2007). Development and regulations regarding car engines and exhaust cleaning systems during the last decade have resulted in a significant decrease of exhaust particulate emissions of vehicular traffic in the European Union. However, the improved engine and exhaust cleaning techniques have had practically no effect on the non-exhaust vehicular emissions. The relative contribution of non-exhaust particulate emissions is therefore increasing, and should be assessed quantitatively (e.g. Keuken, 2006).

The contribution of non-exhaust emissions has commonly been studied by performing stationary field measurements of particle mass-based concentrations at various urban traffic sites. The fractions of various emission source categories can then be quantified, by source apportionment (e.g. AbuAllaban et al., 2003) or statistical analyses (e.g. Bukowiecki et al., 2010).

In some studies, non-exhaust contribution has also been measured by using various mobile measurement laboratories. Kuhns et al. (2001) and Etyemezian et al. (2003a) developed the on-road measurement system TRAKER (Testing Re-entrained Aerosol Kinetic Emissions from Roads) to quantify road dust emissions. Fitz et al. (2005) measured 
$\mathrm{PM}_{10}$ emission factors from roadways using a trailer with sensors mounted in front and behind the vehicle (SCAMPER - System of Continuous Aerosol Monitoring of Particulate Emissions from Roadways). These systems were compared by Langston et al. (2008).

Hussein et al. (2008) installed a similar system as TRAKER into a measurement van called EMMA, and Pirjola et al. (2009) a measurement system into a van called SNIFFER. The main differences between the EMMA and SNIFFER systems were the location of the inlet (behind the front tyres in EMMA and behind the left rear tyre in SNIFFER), different instruments for recording particulate matter (PM) levels, and different loads on the wheel axles. These two systems were compared by Pirjola et al. (2010), and quantitative relationships were established for suspended PM emissions under various conditions.

One of the first methods developed for modelling nonexhaust emissions was called AP-42 (US-EPA, 2011). However, the model has been criticised both for lacking a mechanistic basis and for using as key input a parameter that cannot be accurately measured, i.e. the silt loading (Venkatram, 2000; Düring et al., 2004).

Traction sand and studded tyres in cars are commonly used in the Nordic countries in winter, partly also in autumn and spring. A dust layer is therefore accumulated on road surfaces, and the dust will be released to the atmosphere in spring, after street surfaces become sufficiently dry. The model developed by Omstedt et al. (2005) was the first vehicular non-exhaust emission model that explicitly considered the influence of dust accumulated on roads in winter. The model of Omstedt was further developed to allow the use of the model in air quality forecasting, and evaluated against additional experimental data by Kauhaniemi et al. (2011). This refined model is called FORE (Forecasting Of Road dust Emissions).

The study of Omstedt et al. (2005) also contributed to the construction of a more complex suspension emission model NORTRIP, in which the concept of surface mass balance for dust and moisture has been adopted (Denby and Sundvor, 2012). The latest version of this model has been developed as a Nordic collaboration (Johansson et al., 2012), and is described by Denby and Sundvor (2012) and Denby et al. (2013a).

Road suspension emission models have commonly been evaluated either (i) by combining these with atmospheric dispersion models (e.g. Kauhaniemi et al., 2011; Omstedt et al., 2011) or (ii) by using $\mathrm{NO}_{\mathrm{x}}$ emissions and concentrations as a tracer (e.g. Berger and Denby, 2011; Denby et al., 2013a; Omstedt et al., 2005). In both cases, the predicted concentrations are subsequently compared with air quality measurements. However, both of these methods are indirect in nature, and will therefore involve additional uncertainties to the evaluation.

There are very few studies in which the predictions of a non-exhaust emission model have been directly evaluated against mobile laboratory measurements. All previous studies involve the AP-42 method, combined with the TRAKER and SCAMPER techniques (e.g. Etyemezian et al., 2003b; Langston et al., 2008). Etyemezian et al. (2003b) compared the on-site silt loading method and the default values of AP42 against the TRAKER measurements in Treasure Valley (Idaho), USA. Langston et al. (2008) have reported the studies made with mobile monitoring technologies TRAKER I and II, and SCAMPER, and the AP-42 method in several locations in Clark County in Nevada, USA.

The aim of this paper is to compare the predictions of two road dust emission models, FORE (Kauhaniemi et al., 2011) and NORTRIP (Denby et al., 2013a, b), with emission factor measurements obtained using a mobile van. The mobile laboratory measurements were carried out by the measurement van called SNIFFER (Pirjola et al., 2009, 2012) along two streets in Helsinki, in 2007 and 2008. We also aim to assess the various uncertainties that are associated both with the road suspension emission modelling and with the experimental determination of emission factors using the mobile van.

\section{Materials and methods}

\subsection{Study sites and set-up of the measurement campaigns}

This study is based on measurements using the SNIFFER van, along a route of approximately $20 \mathrm{~km}$ in Helsinki, conducted from 2006 to 2009 (Kupiainen et al., 2009). For this study, we selected the data for two streets, Kaisaniemenkatu (Kaisaniemi Street) and Sörnäisten rantatie (Coast road of Sörnäinen), in 2007 and 2008. The location of these streets and their environment is depicted in Fig. 1. The reason for selecting this particular sub-set of the data was that the road maintenance measures were recorded in detail for those streets during those years. Both of the above-mentioned streets are located in the northeastern part of central Helsinki. The lengths of the measured street segments were 0.50 and $1.25 \mathrm{~km}$ in Kaisaniemenkatu and in Sörnäisten rantatie, respectively.

The SNIFFER road dust measurements were performed during 13 separate days, both in 2007 and in 2008. The measurement van passed the studied road segments once or twice per day. The road dust suspension in Finland is most intensive in spring (March-May), but occurs frequently also in autumn and winter (Kukkonen et al., 1999). Most of the monitoring was therefore performed from March to June; some measurements were done also in August and September. Measurements were performed only when the street surfaces were dry. Detailed information on the traction control and street maintenance events was gathered both in 2007 and 2008. The measurement period of the meteorological data 


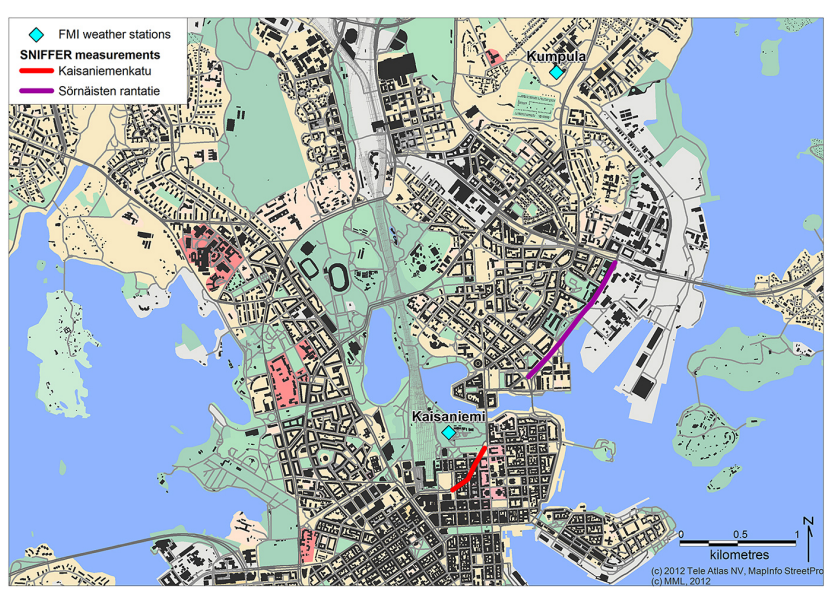

Figure 1. The locations of the street segments (Kaisaniemenkatu, the red line, and Sörnäisten rantatie, the violet line), in which the measurements were conducted, and the weather stations (green diamonds) in central Helsinki in 2007 and 2008 (Kaisaniemi and Kumpula). Buildings are marked in black, parks are presented in green, urban and industrial areas in light brown and grey, and special sites, such as hospitals, in red.

was two whole years (2007-2008). The modelling was also conducted for these two whole years.

Kaisaniemenkatu is oriented approximately from southwest to northeast. Most of this street is located in a fairly narrow street canyon, approximately $21 \mathrm{~m}$ wide, surrounded by approximately $23 \mathrm{~m}$ high buildings. However, the surroundings of the northern end of the street are more open.

According to traffic counts performed by the Helsinki City Planning Department in 2008, the average daily traffic volume in Kaisaniemenkatu was 17602 vehicles day $^{-1}$. This consisted of $66 \%$ passenger cars, $11 \%$ vans and $23 \%$ heavy duty vehicles (in more detail, $18 \%$ buses, $3 \%$ trucks and $2 \%$ trams). Kaisaniemenkatu serves as the main route for local buses from the major bus station to the northeast, which explains the high fraction of buses. The speed limit in Kaisaniemenkatu was $40 \mathrm{~km} \mathrm{~h}^{-1}$. According to the SNIFFER van measurements, the average travel speed was $26 \mathrm{~km} \mathrm{~h}^{-1}$ during the measurement period, both in 2007 and 2008. The actual travel speed is much lower than the speed limit due to frequent stops and traffic congestion.

Sörnäisten rantatie is also oriented approximately from southwest to northeast. The northwestern side of Sörnäisten rantatie is mainly surrounded by about $23 \mathrm{~m}$ high buildings. The southeastern side of the road is mostly open, but in the vicinity of the southern end of the road there are several high buildings (the heights vary from about 40 to $65 \mathrm{~m}$ ).

The ratio of traffic volumes in Hakaniemi Bridge (at the south end of Sörnäisten rantatie) in 2008 and in 2005 is 1.01. According to traffic counts conducted by the Helsinki City Planning Department in 2005, and using the abovementioned ratio, the average daily traffic volume in Sörnäis- ten rantatie can be evaluated to be $50254 \mathrm{veh} \mathrm{day}^{-1}$ in 2008 . This consists of $85 \%$ passenger cars, $11 \%$ vans, and $4 \%$ heavy duty vehicles. The speed limit in Sörnäisten rantatie is 50 or $60 \mathrm{~km} \mathrm{~h}^{-1}$. The average travel speed of the SNIFFER van was $31 \mathrm{~km} \mathrm{~h}^{-1}$ and $30 \mathrm{~km} \mathrm{~h}^{-1}$ during the measurement periods in 2007 and 2008, respectively.

\subsection{Measurements}

\subsubsection{Measurements using the mobile laboratory SNIFFER}

The mobile laboratory SNIFFER can be used to provide measurements of exhaust and non-exhaust particles under real driving conditions (e.g. Pirjola et al., 2004, 2006, 2009, 2010). The instrumentation is installed in a Volkswagen LT35 diesel van. Dust samples are collected behind the left rear tyre through a conical inlet with the surface area of $0.20 \mathrm{~m} \times 0.22 \mathrm{~m}$, into a vertical tube with diameter of $0.10 \mathrm{~m}$. The lower edge of the conical inlet is at a height of $7 \mathrm{~cm}$ above the street surface. Halfway, the tube branches into a $\mathrm{PM}_{10}$ monitor TEOM (Tapered Element Oscillating Microbalance, Series 1400A, Rupprecht \& Patashnick), and an ELPI (Electrical Low Pressure Impactor, Dekati Ltd).

The TEOM monitor was installed to detect 30 s running average mass concentrations every $10 \mathrm{~s}$. The ELPI with the electrical filter stage was used to measure particle number concentrations and size distributions on a time resolution of one second, in the size range of $7 \mathrm{~nm}-10 \mu \mathrm{m}$ (aerodynamic diameter) with 12 channels (Keskinen et al., 1992). Street background $\mathrm{PM}_{10}$ concentration was measured by another ELPI instrument located above the front bumper at an altitude of $0.7 \mathrm{~m}$ above the ground.

A weather station on the vehicle roof at a height of $2.9 \mathrm{~m}$ was used to provide relevant meteorological parameters. Relative wind speed and direction were measured with an ultrasonic wind sensor (Model WAS425AH, Vaisala); the data were subsequently adjusted to allow for vehicle speed and direction. Additionally, a global positioning system (GPS V, Garmin) was used to detect the speed and the driving route. Non-studded winter tyres (also known as friction tyres) were used in the SNIFFER van during the whole measurement period, both in 2007 and 2008.

Data with driving speeds lower than $3 \mathrm{~km} \mathrm{~h}^{-1}$ were excluded from analysis, as there is negligible suspension of road dust at such small speeds. The percentages of excluded data in 2007 and 2008 were $11 \%$ and $24 \%$ in Kaisaniemenkatu, and 5 and $8 \%$ in Sörnäisten rantatie, respectively. The street background $\mathrm{PM}_{10}$ concentrations were subtracted from the $\mathrm{PM}_{10}$ concentrations measured behind the tyre. If the background concentration was higher than the concentration behind the tyre, the resulting value was set to zero. The percentages of zero data in 2007 and 2008 were as follows: 2 and $4 \%$ in Kaisaniemenkatu, and 7 and $8 \%$ in Sörnäisten rantatie, respectively. The total 
number of measured concentrations averaged over $10 \mathrm{~s}$ was in Kaisaniemenkatu 167 and 119 in 2007 and in 2008, and in Sörnäisten rantatie 342 and 266 in 2007 and in 2008.

\subsubsection{Meteorological measurements}

We have used a combination of meteorological data measured at the weather stations at Kaisaniemi and Kumpula (see Fig. 1). Temperature and relative humidity were measured at Kaisaniemi at a height of $2.0 \mathrm{~m}$, precipitation at a height of $1.5 \mathrm{~m}$, and wind speed at a height of $31.0 \mathrm{~m}$. Total cloudiness was measured at Kaisaniemi on a resolution of $10 \mathrm{~min}$; these data were converted to hourly averages. Global radiation was measured at Kumpula as hourly averages.

\subsubsection{Traction control and street maintenance}

The traction control and street maintenance were conducted by the Helsinki City Public Works Department. The timing of these events is presented in Fig. 2. These values were used as an input of the road dust suspension emission models.

Traction control methods included traction sanding, salting and the use of winter tyres; the latter can be studded or friction tyres. In Finland, the use of winter tyres is obligatory on light-duty vehicles from December to February. The use of studded tyres is allowed from 1 November to 31 March or the Monday after Easter, whichever is the later. However, studded tyres can also be used at any other time, if the weather conditions require their use. The maximum share of studded tyres nationally is around $80 \%$ from November to April (Kupiainen, 2007). However, the detailed temporal variation of the percentage of studded tyres is not known. We have therefore assumed that the share of studded tyres increases linearly from $0 \%$ to the maximum usage value of $80 \%$ during October and November, and decreases linearly from 80 to $0 \%$ during April.

The reported sanding and salting days occurred during the period from January to March during both years, and in addition, during November and December in 2008. In 2007, there were 19 sanding and 19 salting events in Kaisaniemenkatu, and 8 salting and 20 sanding events in Sörnäisten rantatie. The corresponding values for sanding and salting in 2008 were 2 and 25 in Kaisaniemenkatu and 0 and 42 in Sörnäisten rantatie. In 2008, relatively milder weather conditions allowed antiskid treatment to be done almost totally by salting on the major routes. However, on smaller roads the number of sanding events was higher.

Street maintenance includes snow ploughing, dust binding by $\mathrm{CaCl}_{2}$, and street cleaning. In the modelling of this study, dust binding and street cleaning events could be allowed for only in the NORTRIP model. In Kaisaniemenkatu, there were no dust binding or street cleaning events in 2007, and 11 dust binding and one cleaning event in 2008. The number of dust binding and cleaning events in Sörnäisten rantatie were 1 and 2 in 2007, and 4 and 1 in 2008, respectively.

The traction control and street maintenance measures were organised in four shifts that each lasted for 6 hours; the first shift started at midnight. In 2007, sanding was conducted mostly in the afternoon and evening, whereas in 2008, more than half of the sanding and salting events took place mainly before the morning rush hours, i.e. during night and very early morning. However, sanding and salting were assumed in both models to occur at $5 \mathrm{a}$.m. at both sites, during both years. This simple assumption was made, as the detailed information on the sanding and salting hours were not available. It is not expected to cause a major uncertainty in the model predictions.

\subsection{Models}

\subsubsection{The FORE road dust emission model}

The FORE model (Forecasting Of Road dust Emissions; Kauhaniemi et al., 2011) can be used to compute the suspension emission factors for particles (in units of $\mu \mathrm{g} \mathrm{veh}^{-1} \mathrm{~m}^{-1}$ ). It is based on the model of Omstedt et al. (2005). The model describes particulate matter generated by the wear of road pavement due to studded tyres, traction sand, and the processes that control the suspension of road dust particles into the air. However, the present model version does not address the emissions from the wear of vehicle components (brake, tyre, and clutch), nor the dependencies of emissions on vehicle speed and fleet composition.

As an input, the model uses hourly time series of meteorological parameters: precipitation, temperature, dew point temperature, relative humidity, wind speed and net radiation (or global radiation and total cloud cover), as well as the share of studded tyres, roughness length of the study site, and the reported or modelled sanding dates. In this study, we have used the reported sanding events as input for the model.

The output of the model is the suspension emission factor for all traffic (i.e. including the whole traffic fleet). The emission factor for suspension is computed separately for socalled sanding and non-sanding periods. The sanding period is defined as the time period during which substantially elevated $\mathrm{PM}_{10}$ concentrations can occur due to the use of traction sand and studded tyres. In Finnish conditions, this period extends from October to May.

The emission factor for suspension of road dust is a product of the so-called reference emission factors, the reduction factor for the moisture content, and a weighted sum of the contributions originated from particles from the wear of pavement and from the traction sand. The baseline values for the model are set by the reference emission factors that depend on the period (sanding or non-sanding), the mass fraction of particles $\left(\mathrm{PM}_{10}\right.$ or $\left.\mathrm{PM}_{2.5}\right)$ and the traffic environment (urban or highway). The reference emission factors can be computed according to a method of Omstedt et al. (2005), 


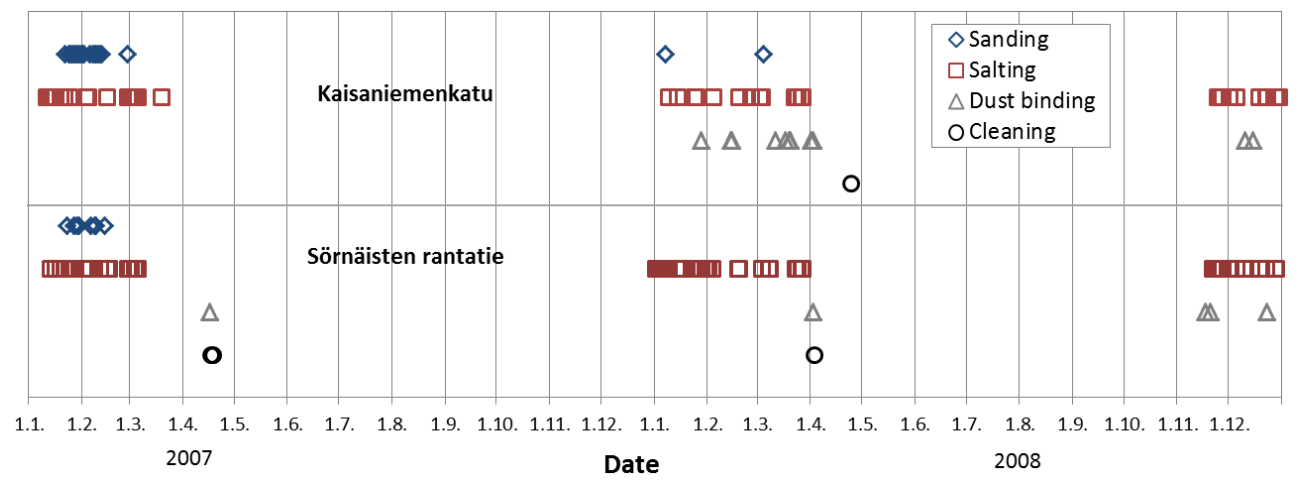

Figure 2. The dates of traction control and street maintenance measures in Kaisaniemenkatu (upper panel) and Sörnäisten rantatie (lower panel) in 2007 and 2008. The figure presents dates of sanding (blue diamonds), salting (red squares), dust binding (grey triangles) and street cleaning (black circles).

which allows the model to be used in wide variety of street locations or a whole city. The use of this method requires the data of both roadside and urban background concentrations of $\mathrm{NO}_{\mathrm{x}}$, and $\mathrm{PM}_{10}$ or $\mathrm{PM}_{2.5}$. As the reference emission factors or the roadside concentrations for the studied streets were not known, we have used the values estimated by Omstedt et al. (2005), i.e. 200 and $1200 \mu \mathrm{g} \mathrm{veh}{ }^{-1} \mathrm{~m}^{-1}$ for nonsanding and sanding periods, respectively. These values were estimated for Hornsgatan in Stockholm.

In the model, equal contributions are assumed for dust layer originating from the road wear and from the traction sand. The dust layer, which is accumulated during wet conditions, depends on traction sanding and the road wear due to the use of studded tyres. During dry conditions the dust layer is reduced by suspension of particles due to vehicle-induced turbulence and during wet conditions by runoff due to precipitation. The dust loading is normalised; the actual loading (in units of $\mathrm{g} \mathrm{m}^{-2}$ ) can be evaluated relative to a maximum value.

Treatment for the change of the moisture of the road surface in the model is based on precipitation, runoff, and evaporation. For computation of the potential evaporation, the roughness length of the surroundings of the street is needed. The roughness lengths were determined visually; this resulted in the roughness lengths of $1.5 \mathrm{~m}$ in Kaisaniemenkatu and $1.1 \mathrm{~m}$ in Sörnäisten rantatie.

\subsubsection{The NORTRIP road dust emission model}

The NORTRIP model (NOn-exhaust Road TRaffic Induced Particle emissions) is a coupled road dust and surface moisture model, with sub-models for calculating road dust emissions and the road surface moisture. It is described in detail in Denby et al. (2013a, b) and Denby and Sundvor (2012). The road dust sub-model is used to compute the direct emissions from road, tyre and brake wear, as well as the emissions from the suspension of accumulated road dust. Road dust is accumulated on the surface when the road surface is moist, as predicted by the surface moisture sub-model. To calculate the road dust emissions, the model requires information concerning total wear rates and the fraction of wear that is in the size fraction $\mathrm{PM}_{10}$. The model can also be used to evaluate the road dust loading due to road wear, salt and sanding (in $\mathrm{g} \mathrm{m}^{-2}$ ).

Brake and tyre wear rates and size fractions are based on literature, e.g. Boulter (2005). The road wear rates are based on the Swedish road wear model (Jacobson and Wågberg, 2007) and will depend on tyre type (studded or non-studded), vehicle speed, and vehicle type (heavy or light). The fraction of total road wear in $\mathrm{PM}_{10}$ is taken to be $20 \%$, based on laboratory experiments (Snilsberg et al., 2008) and comparison to a range of data sets (Denby and Sundvor, 2012). Suspension is treated based on a suspension factor that removes a small fraction of the dust with each vehicle passage. The wear and suspension rates are assumed to be linearly dependent on vehicle speed. In addition, salt and sand can be added to the surface and may also be suspended.

The surface moisture sub-model calculates surface moisture based on the addition of ice or water through precipitation, condensation and wetting during cleaning or salting activities. Moisture is removed by drainage, vehicle spray and evaporation. To calculate the condensation and evaporation, a surface energy balance model for the road surface is applied. Salt added to the road can impact on the surface vapour pressure which will inhibit evaporation.

The model requires information on a number of parameters, not all of which are well known. For example, road wear rates will depend on road pavement characteristics and may vary by a factor of four. No pavement data were available for the studied streets in Helsinki; the default value for the Swedish road wear model was therefore used. The suspension factor is also not well known, and it may vary from road to road depending on the road surface macrotexture. Previous studies (Denby et al., 2013a) have shown a reasonable range of values to be between $0.5 \times 10^{-6}$ and 
$5 \times 10^{-6} \mathrm{veh}^{-1}$. The relevant total wear rates, $\mathrm{PM}_{10}$ fraction of total wear and vehicle induced suspension rates used in this study are provided in Table 1.

Input data requirements include metadata on road and street canyon configurations, traffic data (vehicle counts, vehicle types, tyre types and vehicle speeds) and meteorological data concerning wind speed, temperature, radiation, cloud cover, and humidity. In addition, road maintenance activity information concerning addition of salt and sand to the road surface is required. For sand, information concerning its size distribution is also required, though this was also not known in this study. A fraction of $0.2 \% \mathrm{PM}_{10}$ of the total sand mass was applied, based on previous measurements conducted in Stockholm (Denby and Sundvor, 2012). In the application of the model in this article, the percentage of sand that is $\mathrm{PM}_{10}$ was assumed to be constant, i.e. no grinding of the sand was included. The observational data were not sufficient to properly parameterise this effect.

Output of the model is the emission from road, tyre, brake, and wear sources, as well as emissions from salt and from sand in the size fraction $\mathrm{PM}_{10}$.

\subsection{The post-processing of measured and modelled values}

\subsubsection{Post-processing of the mobile van measurements}

The SNIFFER van is used to measure particulate matter concentrations behind a tyre. These values therefore need to be converted to emission coefficients. To derive these equations, Pirjola et al. (2012) conducted PM $_{10}$ concentration measurements upwind and downwind from a street, following the TRAKER method described by Gertler et al. (2006). An air quality measurement trailer was located on the upwind side, and a measurement tower of $10 \mathrm{~m}$ height was mounted on the downwind side. The tower was installed with three DustTraks (Model 8530, TSI) at the altitudes of 1.9, 2.9 and $4.3 \mathrm{~m}$. A fourth DustTrak was installed on the roof of the trailer.

The SNIFFER van was run between the trailer and the tower at speeds of 30 and $50 \mathrm{~km} \mathrm{~h}^{-1}$. At least 10 passings were recorded in both directions of the road without interference from other vehicle traffic. Emission factors (EFs) were calculated according to Gertler et al. (2006):

$\mathrm{EF}=\sum_{i=1}^{n} \sum_{j=1}^{3} u_{i} \cos \theta_{i} C_{i j} \Delta z_{j} \Delta t_{i}$,

where $n$ is the number of data points (here 10), $u_{i}$ is the wind speed in $\mathrm{m} \mathrm{s}^{-1}, \theta_{i}$ is the angle between the wind direction and a line perpendicular to the road, $C_{i j}$ is the $i$ th $\mathrm{PM}_{10}$ concentration $\left(\mu \mathrm{g} \mathrm{m}^{-3}\right)$ measured at the $j$ th downwind monitor over the period $\Delta t_{i}(\mathrm{~s})$, and $\Delta z_{j}(\mathrm{~m})$ is the vertical interval represented by the $j$ th monitor.

Because dust layer and vehicle speed affect emission factors, it would be useful to derive a relationship between the measured suspended $\mathrm{PM}_{10}$ concentration behind SNIFFER's left rear tyre and SNIFFER's emission factor. Therefore, during the upwind-downwind tests SNIFFER was used to simultaneously measure the suspended $\mathrm{PM}_{10}$ concentration by the TEOM (10 s values) behind the tyre. When the resulted emission factors were plotted as a function of the measured $\mathrm{PM}_{10}$ concentrations, the following empirical equations were obtained:

$$
\begin{aligned}
& \mathrm{EF}=18.46 \times \mathrm{PM}_{10}^{0.55}, \text { if } \mathrm{PM}_{10}>2000 \mu \mathrm{g} \mathrm{m}^{-3} \\
& \mathrm{EF}=0.6093 \times \mathrm{PM}_{10}, \quad \text { if } \mathrm{PM}_{10} \leq 2000 \mu \mathrm{g} \mathrm{m}^{-3},
\end{aligned}
$$

where $\mathrm{PM}_{10}$ is the concentration measured by SNIFFER behind the tyre, and EF is Sniffer's emission factor $\left(\mathrm{g} \mathrm{km}^{-1}\right)$. Considering the inaccuracies of the measurements, the uncertainty of this numerical fitting was about $20 \%$.

The upwind and downwind measurements were also performed for a passenger car Opel Vectra. We found that the emission factors of the passenger car were $(73 \pm 6) \%$ of the SNIFFER's emission factors (Pirjola et al., 2012). AbuAllaban et al. (2003) measured $\mathrm{PM}_{10}$ emission rates for road dust from light-duty vehicles (LDVs) in the range of 40$780 \mathrm{~m} \mathrm{~km}^{-1}$ and from heavy-duty vehicles (HDVs) in the range of $230-7800 \mathrm{mg} \mathrm{km}^{-1}$ depending on the degree of silt loading. Based on these experiments, the emission factors for HDVs can be estimated to be approximately 9-10 times the emission factors of passenger cars.

As the models use hourly values for all the parameters, we have computed hourly averaged values, based on the $10 \mathrm{~s}$ averaged $\mathrm{PM}_{10}$ concentrations, for each monitoring day. During the monitoring days SNIFFER was used to measure $\mathrm{PM}_{10}$ concentrations over the whole city route (of approximately the length of $20 \mathrm{~km}$ ), which was always driven twice, lasting in total about 2.5-3 h. However, the route segments on Kaisaniemenkatu and Sörnäisten rantatie lasted only 30 $130 \mathrm{~s}$ and $40-240 \mathrm{~s}$, respectively (after the times for stopping and vehicle speeds smaller than $3 \mathrm{~km} \mathrm{~h}^{-1}$ were excluded). The mean value of the available TEOM records was assumed to represent the hourly value. The temporal representativity of the measured values is therefore limited, and the scatter of the data points is expected to be substantial.

\subsubsection{Post-processing of model predictions}

The emission factors modelled by the FORE and NORTRIP suspension models represent the whole traffic fleet $\left(\mathrm{EF}_{\text {tot }}\right)$, whereas the measured values represent those for a van $\left(\mathrm{EF}_{\mathrm{van}}\right)$. The emission factors for the whole traffic therefore need to be converted to those for a van, using the information concerning the traffic fleet composition at the considered street segments. The derivation of this conversion equation is presented in Appendix A. Adding an additional factor based on the NORTRIP model, $V_{\mathrm{van}} / V_{\mathrm{veh}}$, the final result can be presented as

$\mathrm{EF}_{\mathrm{van}}=\frac{\mathrm{EF}_{\mathrm{tot}}}{\left(f_{\mathrm{pCar}} \cdot r_{\mathrm{pCar}}+f_{\mathrm{van}}\right) \cdot\left(\text { frac }_{\mathrm{ldv}}+\text { frac }_{\mathrm{hdv}} \cdot r_{\mathrm{hdv}}\right)} \cdot \frac{V_{\mathrm{van}}}{V_{\mathrm{veh}}}$, 
Table 1. Values of parameters used in the NORTRIP model in this study. The values of the wear rates, separately for road, tyres and brakes, and road dust suspension rates are presented for studded, winter and summer tyres. The term $\mathrm{PM}_{10}$ fraction refers to the fraction of wear and suspension particles in the size range less than $10 \mu \mathrm{m}$ of all particles for light-duty vehicles used in the NORTRIP model calculations. The $\mathrm{PM}_{10}$ fraction is the same for all vehicles. Wear and suspension rates for heavy-duty vehicles are considered to be 5 and 10 times larger, respectively, compared with light-duty vehicles. The reference speed for all of these parameters is $50 \mathrm{~km} \mathrm{~h}^{-1}$.

\begin{tabular}{lrrrr}
\hline & $\begin{array}{r}\text { Studded } \\
\text { tyres }\end{array}$ & $\begin{array}{r}\text { Winter } \\
\text { tyres }\end{array}$ & $\begin{array}{r}\text { Summer } \\
\text { tyres }\end{array}$ & $\begin{array}{r}\mathrm{PM}_{10} \\
\text { fraction }(\%)\end{array}$ \\
\hline Road wear $\left(\mathrm{g} \mathrm{km}^{-1} \mathrm{veh}^{-1}\right)$ & 2.00 & 0.10 & 0.10 & 20 \\
Tyre wear $\left(\mathrm{g} \mathrm{km}^{-1} \mathrm{veh}^{-1}\right)$ & 0.10 & 0.10 & 0.10 & 10 \\
Brake wear $\left(\mathrm{g} \mathrm{km}^{-1} \mathrm{veh}^{-1}\right)$ & 0.01 & 0.01 & 0.01 & 80 \\
Default road dust & $5 \times 10^{-6}$ & $5 \times 10^{-6}$ & $5 \times 10^{-6}$ & 20 \\
suspension rate $\left(\mathrm{veh}^{-1}\right)$ & & & & \\
\hline
\end{tabular}

where $f_{\mathrm{pCar}}$ and $f_{\mathrm{van}}$ are the fractions of passenger cars and vans of the LDVs, $r_{\mathrm{pCar}}$ is the ratio of suspension rates for passenger car to van, frac $_{\mathrm{ldv}}$ and frac $\mathrm{c}_{\mathrm{hdv}}$ are the fractions of LDVs and HDVs of the total traffic, $r_{\mathrm{hdv}}$ is the ratio of suspension rates for HDVs to LDVs, $V_{\text {van }}$ is the speed of the measurement van and $V_{\mathrm{veh}}$ is the average vehicle speed. We have assumed here $r_{\mathrm{pCar}}$ to be equal to 0.7 , according to Pirjola et al. (2012), and $r_{\mathrm{hdv}}$ to be equal to 10 , according to Abu-Allaban et al. (2003).

Both the wear and suspension EFs are linearly dependent on vehicle speed in the NORTRIP model. The last factor on the right-hand side of Eq. (4), $V_{\text {van }} / V_{\text {veh}}$, allows for this dependency. Light and heavy duty vehicles are assumed to have the same travel speed in the NORTRIP model. We have used the average travel speeds of the SNIFFER van; these were $26 \mathrm{~km} \mathrm{~h}^{-1}$ in Kaisaniemenkatu and $31 \mathrm{~km} \mathrm{~h}^{-1}$ in Sörnäisten rantatie. Vehicle speed has not been taken into account in the FORE model; for the computations with this model, we have therefore not included the term $V_{\text {van }} / V_{\text {veh }}$.

\section{Results}

\subsection{Comparison of the predictions of the FORE model and the measurements}

We have used Eq. (4) to convert the suspension EFs of all traffic to those for a van. The modelled values for both the emission factors for all traffic and for a van were compared against the measured suspension emission factors. A comparison of the predicted and measured hourly averages is presented in Fig. 3. The measured data are highly variable. The high variability was caused by the challenges in the measurements, including the limited temporal representativity of the data.

The maximum $\mathrm{PM}_{10}$ concentrations and suspension emission factors in Helsinki have most commonly been measured in the later part of March and early part of April, although the year-to-year variation has been found to be substantial (Kukkonen et al., 1999, 2000; Kupiainen et al.,
2009). The model can reproduce the seasonal variability of the measured suspension emission factors fairly well both in Kaisaniemenkatu and Sörnäisten rantatie. Both the modelled and measured suspension emission factors were highest during late winter and spring, and lowest in summer. Both the highest measured and modelled values in 2007 occurred from February to April at both locations. In 2008, the highest measured values also occurred from February to April; however, the agreement of the modelled and measured seasonal variation was relatively worse. The measured suspension emission factors were substantially under-predicted at both locations, including especially the highest values from February to April.

Selected statistical measures for the agreement of the measured and predicted hourly time series are presented in $\mathrm{Ta}$ ble 2 . The index of agreement (IA) and the correlation coefficient squared $\left(R^{2}\right)$ are measures of the correlation of the modelled and measured time series, while fractional bias (FB) is a measure of the agreement of the mean values. The values of the statistical parameters, such as the index of agreement and the correlation coefficient, indicate from a moderate to weak correlation of the individual predicted and measured data values. In Kaisaniemenkatu, the predicted emission factors for all traffic are closer to measured emission factors, compared with the modelled emission factors for a van. In Sörnäisten rantatie, the predicted emission factors for all traffic and for a van are at approximately the same level.

\subsection{Comparison of the predictions of the NORTRIP model and the measurements}

In the case of the NORTRIP model, the evaluation of the input values for the model includes additional uncertainties. Before selecting the values for the actual model versus measurements comparison, we first conducted a sensitivity analysis. We evaluated the influence of two key input parameters: the suspension rate and the average travel speed. The definitions of the cases for these analyses are presented in Table 3. 

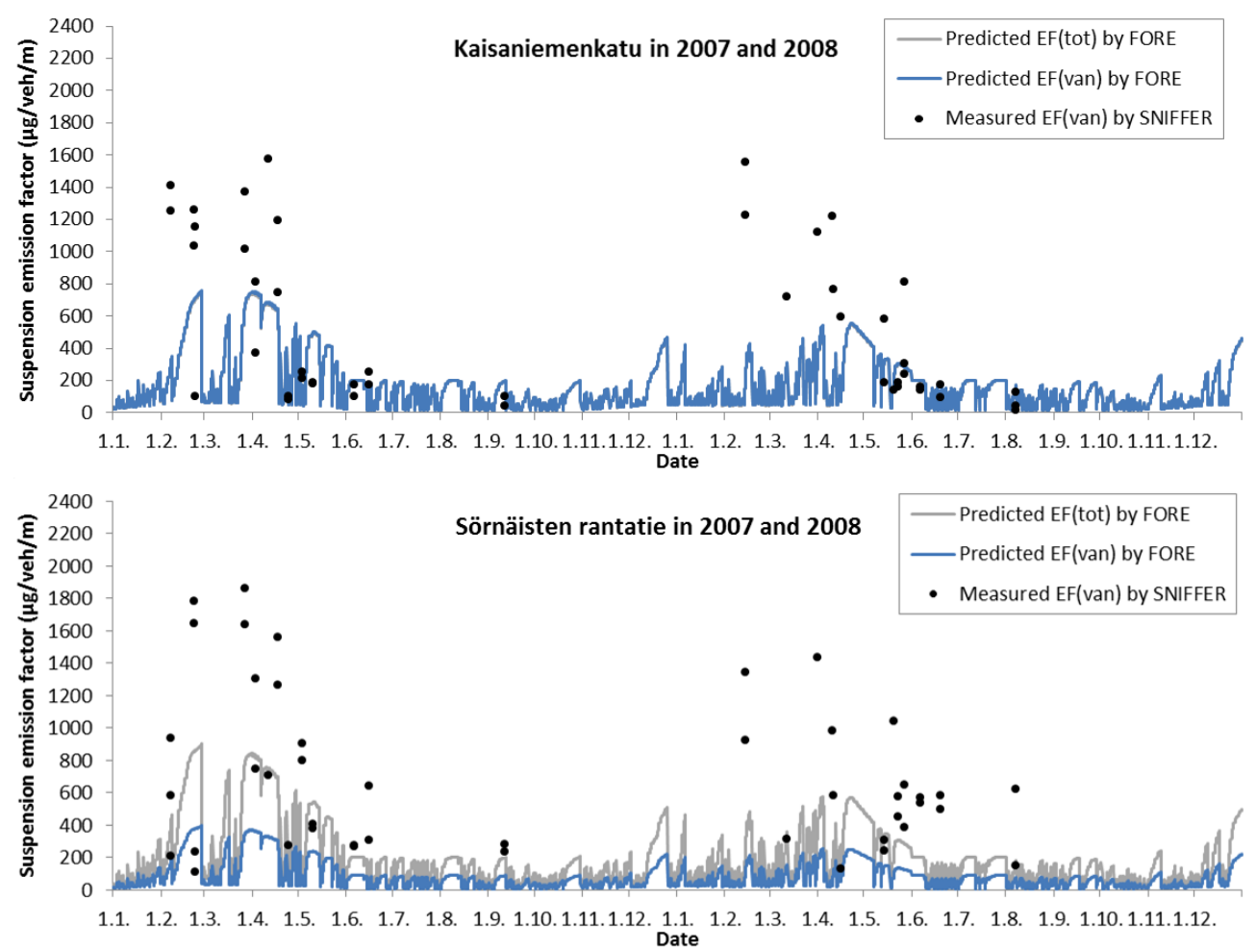

Figure 3. Hourly average suspension emission factors for all traffic $\left(\mathrm{EF}_{\mathrm{tot}}\right)$ and for a van $\left(\mathrm{EF}_{\mathrm{van}}\right)$, predicted using the FORE model and measured in Kaisaniemenkatu (upper panel) and Sörnäisten rantatie (lower panel) in 2007 and 2008. In the lower panel, the ratio of predicted $\mathrm{EF}_{\text {tot }}$ and predicted $\mathrm{EF}_{\mathrm{van}}$ is about 0.99 ; the predicted lines therefore overlap.

Table 2. The statistical analysis of the agreement of hourly average suspension emission factors for all traffic $\left(\mathrm{EF}_{\text {tot }}\right)$ and for a van $\left(\mathrm{EF}_{\mathrm{van}}\right)$, predicted by the FORE model and measured in Kaisaniemenkatu and Sörnäisten rantatie in 2007-2008.

\begin{tabular}{lrr|rr}
\hline & \multicolumn{2}{c|}{ Kaisaniemenkatu } & \multicolumn{2}{c}{ Sörnäisten rantatie } \\
\cline { 2 - 5 } & $\mathrm{EF}_{\text {tot }}$ & $\mathrm{EF}_{\text {van }}$ & $\mathrm{EF}_{\text {tot }}$ & $\mathrm{EF}_{\text {van }}$ \\
\hline Index of agreement $(\mathrm{IA})$ & 0.56 & 0.48 & 0.60 & 0.60 \\
Factor-of-two $(\mathrm{F} 2 ; \%)$ & 47 & 13 & 55 & 53 \\
Correlation coefficient $\left(R^{2}\right)$ & 0.23 & 0.23 & 0.23 & 0.23 \\
Fractional bias $(\mathrm{FB})$ & -0.59 & -1.23 & -0.50 & -0.49 \\
Average $\mathrm{EF}_{\mathrm{p}}\left(\mu \mathrm{g} \mathrm{veh} \mathrm{g} \mathrm{m}^{-1}\right)$ & 383 & 168 & 326 & 331 \\
Average $\mathrm{EF}_{\mathrm{m}}\left(\mu \mathrm{g} \mathrm{veh}^{-1} \mathrm{~m}^{-1}\right)$ & & 702 & & 547 \\
Number of data points $(N)$ & & 45 & & 47 \\
\hline
\end{tabular}

The parameter called suspension rate has an impact on the rate at which the dust is removed from the street surface. The optimal suspension rate was found to range from 0.5 to 5 per million, based on model sensitivity analyses in Stockholm, Oslo, Helsinki and Copenhagen (Denby and Sundvor, 2012). However, the suspension rate parameter is site specific, and it is dependent on local factors, such as road surface texture and driving characteristics. As the exact suspension rates for the study sites were not known, we have selected two values: the default value of suspension rate for LDVs used in the model $\left(2 \times 10^{-6} \mathrm{veh}^{-1}\right)$ and the optimal value found for the measurements at Hornsgatan, Stockholm $\left(5 \times 10^{-6}\right.$ veh $\left.^{-1}\right)$.
In both cases, the suspension rate for HDVs was considered to be 10 times higher than for LDVs.

The lower average travel speed values are equal to the measured average travel speeds of the van (26 and $30 \mathrm{~km} \mathrm{~h}^{-1}$ ), and the upper values are equal to the speed limits at the selected street segments $\left(40\right.$ and $\left.50 \mathrm{~km} \mathrm{~h}^{-1}\right)$, in Kaisaniemenkatu and Sörnäisten rantatie, respectively.

The results of this sensitivity study are presented in Fig. 4. The emission factors in the selected four cases most commonly vary by a factor of two or three. As expected, at both study sites, the highest suspension emission factors were obtained in case 4 , in which the suspension rates and travel 
Table 3. The suspension rates of light-duty vehicles (LDVs) and the travel speeds selected for the sensitivity analyses of the NORTRIP model.

\begin{tabular}{ccc|cc}
\hline Case & \multicolumn{2}{c|}{ Kaisaniemenkatu } & \multicolumn{2}{c}{ Sörnäisten rantatie } \\
\cline { 2 - 5 } & $\begin{array}{c}\text { Suspension rate } \\
\text { of LDVs }\left(\mathrm{veh}^{-1}\right)\end{array}$ & $\begin{array}{c}\text { Travel speed } \\
\left(\mathrm{km} \mathrm{h}^{-1}\right)\end{array}$ & $\begin{array}{c}\text { Suspension rate of } \\
\text { LDVs }\left(\mathrm{veh}^{-1}\right)\end{array}$ & $\begin{array}{c}\text { Travel speed } \\
\left(\mathrm{km} \mathrm{h}^{-1}\right)\end{array}$ \\
\hline 1 & $2 \times 10^{-6}$ & 26 & $2 \times 10^{-6}$ & 30 \\
2 & $2 \times 10^{-6}$ & 40 & $2 \times 10^{-6}$ & 50 \\
3 & $5 \times 10^{-6}$ & 26 & $5 \times 10^{-6}$ & 30 \\
4 & $5 \times 10^{-6}$ & 40 & $5 \times 10^{-6}$ & 50 \\
\hline
\end{tabular}

speeds were the highest. Correspondingly, the lowest suspension emission factors were obtained in case 1 . We have selected case 4 for a more detailed comparison with the measurements.

A comparison of the hourly average suspension emission factors for all traffic $\left(\mathrm{EF}_{\text {tot }}\right)$ and for a van $\left(\mathrm{EF}_{\mathrm{van}}\right)$ predicted by the NORTRIP model and the measured values is presented in Fig. 5. Statistical measures for the agreement of the measured and predicted hourly time series are presented in Table 4 .

Similarly with the results for the FORE model, the model predicts fairly well the seasonal variation of the measured suspension emission factors at both sites, and the emission factors for a van are clearly under-predicted at both locations. However, the levels of hourly average suspension emission factors for all traffic are predicted fairly well.

\section{Analysis of the uncertainties of measured and modelled results}

Several of the processes associated with the formation and release to the air of suspended road dust are currently not sufficiently known and understood. We have therefore attempted to list and describe some of the most important sources of uncertainty both in the measurements and modelling. The differences between the predicted and measured suspension emission factors can be caused by uncertainties of (i) the measured data and their post-processing, (ii) the input data of the road suspension emission models, (iii) the deficiencies and limitations of the road suspension emission models and (iv) the post-processing of the modelled data.

\subsection{The measured data and their post-processing}

The total number of measurements in the present campaign was limited. There were 119-342 valid SNIFFER records, and therefore 20-25 measured hourly emission factors could be determined, per site and per year. The limited temporal representativity of the SNIFFER measurements causes a substantial scatter and uncertainties to the measured data. The measurements consisted of $30 \mathrm{~s}$ running average concentrations, archived every $10 \mathrm{~s}$. Hourly averages were sub- sequently computed based on the $10 \mathrm{~s}$ averaged SNIFFER emission factors; there were from 3 to 24 records per hour.

In order to evaluate the predictions against measurements, it was also necessary to post-process the measured data. The measured concentrations were converted to emission factors by using empirical conversion equations. These were based on previous measurements conducted in Helsinki, along two streets in two years (Pirjola et al., 2012). The accuracy of these equations was estimated to be approximately $20 \%$. These measurements were conducted in the same city, and several of the relevant conditions can be considered to be similar to those in the present measurement campaigns. However, the spatial and temporal representativity of these equations has not yet been quantitatively evaluated.

The measurements were done with a vehicle that was equipped with non-studded winter tyres during the whole study period. However, both models allow also for suspension emissions from vehicles that are equipped with studded tyres. Clearly, the type of tyre influences the resuspension emission factors. However, the variability in emission factors between studded and studless tyres was found to be moderate by Kupiainen and Pirjola (2011) - it varied from 10 to $20 \%$, at vehicle speeds of 40 and $50 \mathrm{~km} \mathrm{~h}^{-1}$.

\subsection{The input data of the road suspension emission models}

There are substantial uncertainties in the input data required by the road dust emission models. We used an extensive and detailed data base regarding the traction control and street maintenance (Kupiainen et al., 2009) that contains detailed information on the timing of sanding and salting events in the studied streets. Nevertheless, it was not possible to obtain all relevant data with high accuracy. The timing of these events was reported in 6-hourly periods, and the exact hour of the day is not known. The reported events also refer only to traction control and street maintenance on lanes of the considered street segments. There is no information regarding sand and other material on sidewalks, on adjoining streets, and on parking and green areas; however, these can have an influence on dust loads of the studied streets. The adjoining minor streets and other surrounding areas are commonly cleaned 

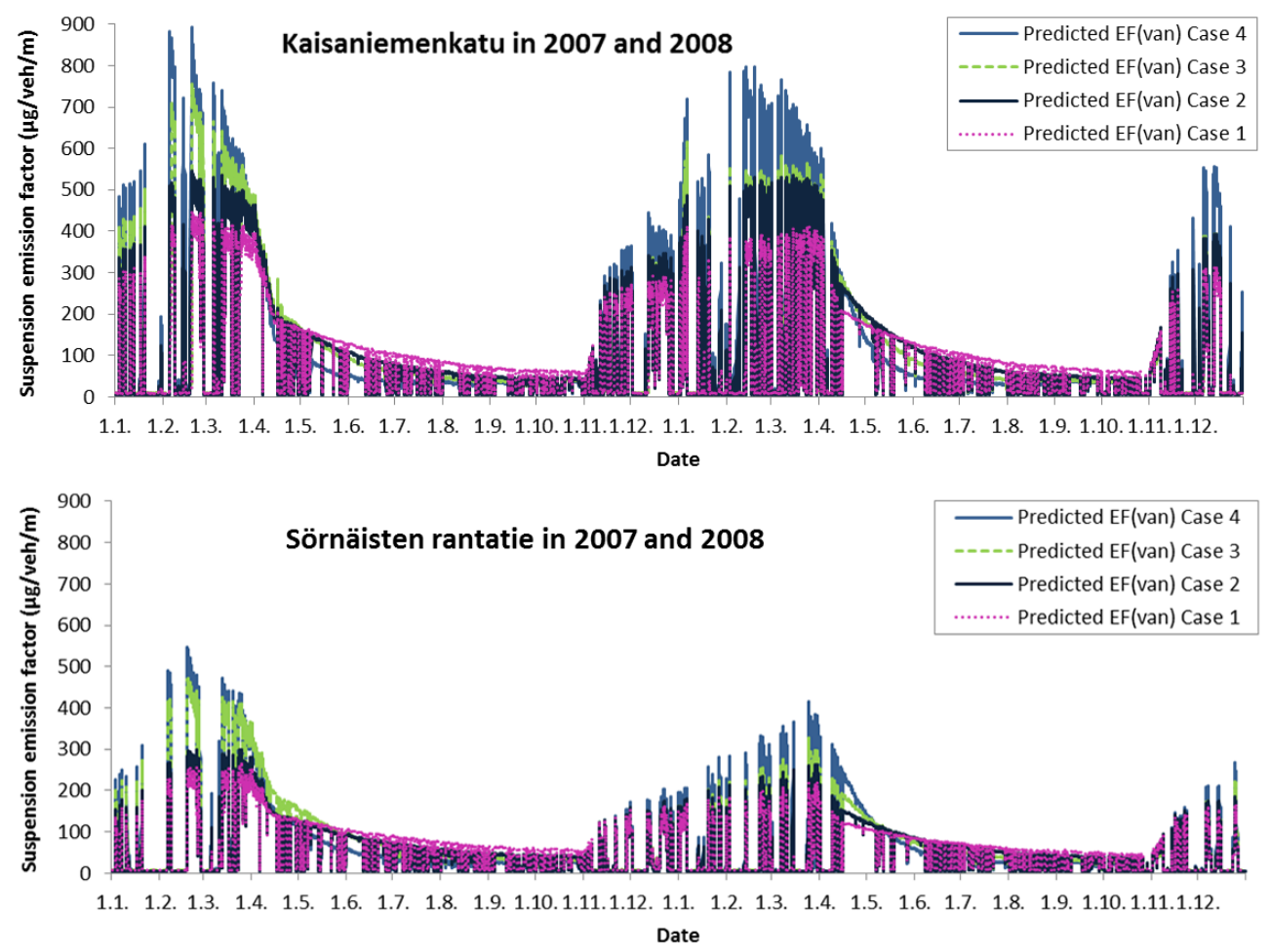

Figure 4. Hourly average suspension emission factors predicted by the NORTRIP model in Kaisaniemenkatu (upper panel) and in Sörnäisten rantatie (lower panel) in 2007 and 2008, for four sensitivity analysis cases (defined in Table 3).
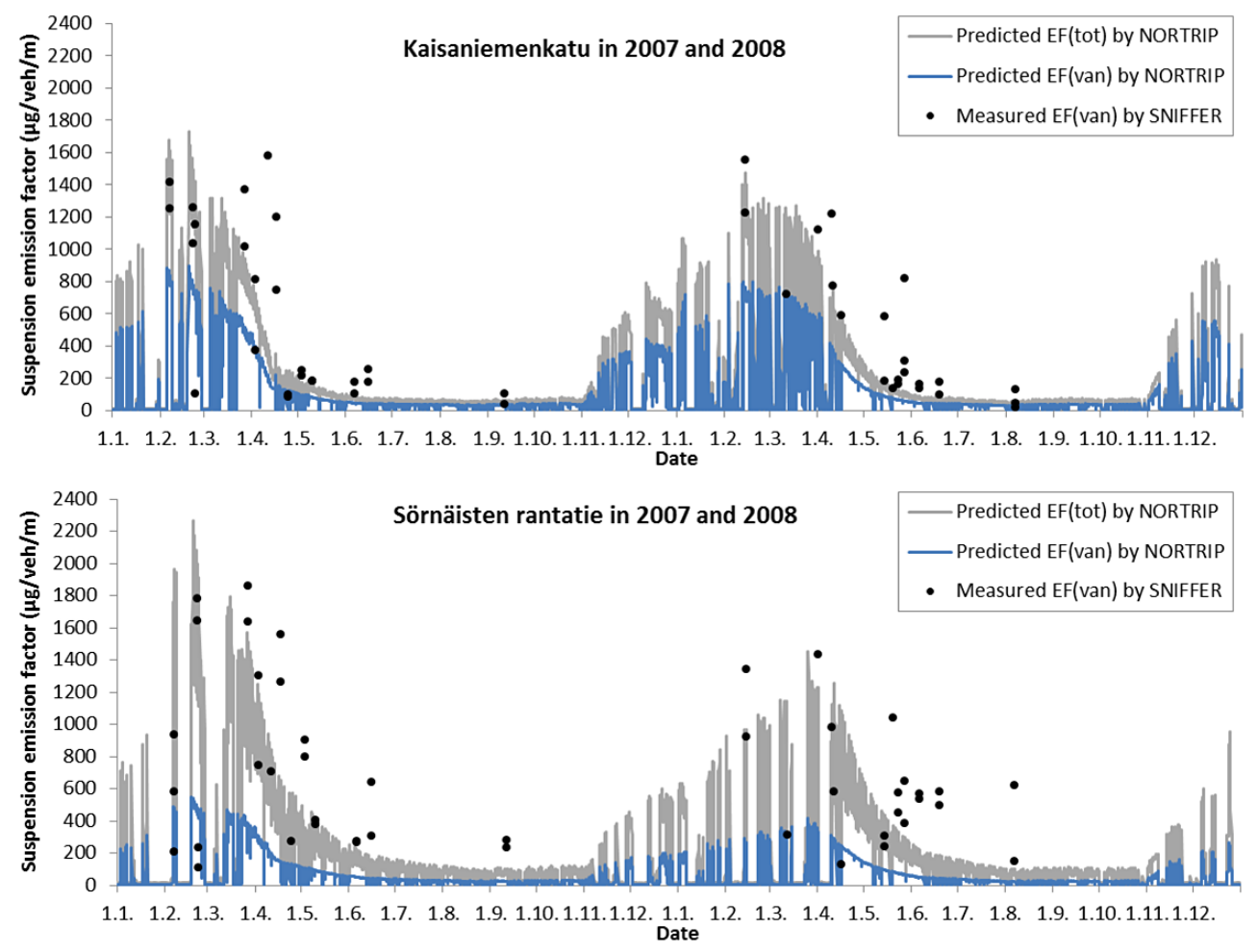

Figure 5. Hourly average suspension emission factors for all traffic $\left(\mathrm{EF}_{\mathrm{tot}}\right)$ and for a van $\left(\mathrm{EF}_{\mathrm{van}}\right)$, predicted using the NORTRIP model and measured in Kaisaniemenkatu (upper panel) and Sörnäisten rantatie (lower panel) in 2007 and 2008. 
Table 4. The statistical analysis of the agreement of hourly average suspension emission factors for all traffic $\left(\mathrm{EF}_{\mathrm{tot}}\right)$ and for a van $\left(\mathrm{EF}_{\mathrm{van}}\right)$, predicted by the NORTRIP model assuming case number 4, and measured in Kaisaniemenkatu and Sörnäisten rantatie in 2007-2008.

\begin{tabular}{lrr|rr}
\hline & \multicolumn{3}{c|}{ Kaisaniemenkatu } & \multicolumn{2}{c}{ Sörnäisten rantatie } \\
\cline { 2 - 5 } & $\mathrm{EF}_{\text {tot }}$ & $\mathrm{EF}_{\text {van }}$ & $\mathrm{EF}_{\text {tot }}$ & $\mathrm{EF}_{\text {van }}$ \\
\hline Index of agreement (IA) & 0.60 & 0.46 & 0.84 & 0.71 \\
Factor-of-two (F2; \%) & 40 & 7 & 64 & 28 \\
Correlation coefficient $\left(R^{2}\right)$ & 0.09 & 0.09 & 0.52 & 0.52 \\
Fractional bias $(\mathrm{FB})$ & -0.30 & -1.28 & -0.24 & -0.75 \\
Average $\mathrm{EF}_{\mathrm{p}}\left(\mu \mathrm{g} \mathrm{veh} \mathrm{v}^{-1} \mathrm{~m}^{-1}\right)$ & 517 & 154 & 430 & 250 \\
Average $\mathrm{EF}_{\mathrm{m}}\left(\mu \mathrm{g} \mathrm{veh}^{-1} \mathrm{~m}^{-1}\right)$ & & 702 & & 547 \\
Number of data points $(N)$ & & 45 & & 47 \\
\hline
\end{tabular}

later than the main roads and streets. In Kaisaniemenkatu, sand is also used by trams to increase friction in braking.

Both models used the best representative meteorological data, measured at the weather station of Kaisaniemi. However, some relevant meteorological variables can vary substantially within the city (e.g. Wood et al., 2013). In particular, the occurrence and intensity of precipitation can vary significantly both temporally and spatially. The influence of short term or weak showers could be under-predicted, as hourly average values are used as input for the models.

According to numerous studies, e.g. Kuhns et al. (2001), Etyemezian et al. (2003b) and Pirjola et al. (2009), the suspended $\mathrm{PM}_{10}$ concentration measured by mobile monitoring techniques is dependent on travel speed; PM levels are higher at higher speeds. However, the average travel speed of the measurement van varied substantially within each hour and within the study period. It was not possible to allow for all of those travel speed variations, and we used hourly average values in the modelling. It is possible to allow for the travel speed dependence in the NORTRIP model, if the detailed data are available.

\subsection{The deficiencies and limitations of the road dust suspension emission models}

The reference emission factors are critical parameters for the FORE model, as these set the suspension baseline values. Unfortunately, measured reference emission factors were not available for the study sites. We therefore used the reference emission factors that were previously estimated for Hornsgatan in Stockholm. Although the climatic conditions and the shares of studded tyres are similar in Stockholm and Helsinki, there are also differences, when one considers the details of the measurement locations. In particular, the share of HDVs is larger in Kaisaniemenkatu than in Hornsgatan. Hornsgatan is located in a street canyon, and although most of the Kaisaniemenkatu segment is also a street canyon, only one side of Sörnäisten rantatie is surrounded by major buildings.
One of the key input parameters for the NORTRIP model is the suspension rate. Since the suspension rates for the study sites were not known, we tested the sensitivity of the model predictions in terms of two values of this parameter and two values of the average travel speed. The results from this comparison indicate differences of a factor of two or three in the emission factors. In addition, there are also uncertainties in the wear and suspension rates of the NORTRIP model. In previous comparisons with other data sets (Denby et al., 2013b), the NORTRIP model could predict longer-term mean concentrations within $35 \%$ of those observed. However, for short-term predictions (e.g. hourly values), this inaccuracy can be significantly higher. More information especially concerning the pavement type would reduce some of this uncertainty.

Neither of the models used can distinguish between (i) the suspension caused by vehicle tyres and (ii) the suspension caused by vehicle-induced turbulence. The observations are performed behind a wheel of a laboratory van. This location has been selected, as the suspension caused by vehicle tyres is probably the most important mechanism for LDVs (such as the SNIFFER van). However, some fraction of suspension will also be caused by the vehicle-induced turbulence associated with the whole traffic flow. Neither measurements nor models can delineate between these two mechanisms for causing suspension emissions. Clearly, the suspension caused by traffic-induced turbulence is more significant for HDVs than for LDVs.

\subsection{The post-processing of the modelled data}

In order to compare model predictions against mobile measurements, the predicted emission factors need to be adjusted for the particular vehicle or traffic conditions. For example, the AP-42 method requires the average weight of the traffic fleet as an input (US-EPA, 2011). For the comparison between AP-42 and TRAKER/SCAMPER techniques, the weight of the mobile monitoring vehicle is used as a model input. 
In this study, the predictions of both road dust emission models were converted to the suspension emission factors corresponding to a van, by using coefficients of Pirjola et al. (2012) and Abu-Allaban et al. (2003) for the suspension rates of different vehicle types, and the shares of different vehicle types at the study sites. However, this conversion adds one more source of uncertainty to the study.

\section{Conclusions}

We have compared suspension emissions using a mobile monitoring system with predicted road dust emissions computed by two road dust emission models (FORE and NORTRIP). Such a quantitative comparison has not previously been reported in the reviewed literature. However, there are numerous sources of inaccuracy both (i) in conducting suspension emission measurements in an urban traffic environment, and (ii) in determining the input values for the models and conducting the suspension modelling. Consequently, more extensive and versatile measurement campaigns in various environments and conditions would be welcome for the refinement of suspension emission models.

The seasonal variation of the suspension emission factors was predicted fairly well by both models. Both the modelled and measured suspension emission factors were highest during late winter and spring, and lowest in summer. However, the measured suspension emission factors were substantially under-predicted at both locations, including especially the highest values from February to April.

There can be many reasons for the under-predictions. The processes associated with the formation and release to the air of suspended road dust are currently not sufficiently known and understood. It is also challenging to measure accurately and comprehensively all relevant model input parameters. In general, the differences between the predicted and measured suspension emission factors can be caused by the uncertainties of (i) the measured data and their post-processing, (ii) the input data of the road suspension emission models, (iii) the deficiencies and limitations of the road suspension emission models, and (iv) the post-processing of the modelled data.

Both of these road dust emission models have previously been evaluated indirectly, by comparison to stationary air quality measurements. In these previous studies, no systematic under-prediction of emissions or concentrations was detected. The sensitivity study conducted in the case of the NORTRIP model showed that a reasonable variation of two key input parameters resulted in predictions for the emission coefficients that varied by a factor of two or three. The uncertainties of model input data would therefore probably be sufficient for causing the detected difference of measurements and modelling.
In the future, more detailed and extensive measurement campaigns would be welcome. The van measurements should include a substantial number of continuously conducted successive drives back and forth along the studied street segment. Such a measurement set-up would aim to achieve as good a temporal coverage as possible during the selected measurement days and hours. The measurement data should include both peak suspension periods in spring and lower values during other seasons. If possible, these measurements should also be carried out for a single vehicle (i.e. the measurement van), without interference from other vehicle traffic. In measurements including also the other traffic, there should be detailed monitoring of traffic volumes of various vehicle categories, and continuous monitoring of travel speeds.

The campaign should ideally include also upwind and downwind measurements of ambient $\mathrm{PM}_{10}$ and $\mathrm{NO}_{\mathrm{x}}$, the latter to be used as a tracer of vehicle-originated pollutants. These measurements would facilitate direct evaluation of the conversion of the concentration measurements at the van to emission coefficients. The campaign should also include onsite meteorological measurements, especially for precipitation, to avoid inaccuracies caused by the spatial variation of the relevant meteorological quantities in an urban area.

It would be useful to continuously measure the moisture on the street surface; designated equipment is available for this purpose. A road weather model could also be used for a detailed evaluation of the state of the road surface. Measurements of the street pavement structure could be used for a more accurate evaluation of the dust absorption and run-off from the road. It is also valuable to record all the street maintenance activities, such as the use of traction sand and salt, and street cleaning procedures, on a fine temporal resolution. The information regarding the street maintenance activities should ideally also include the mass of used traction sand and salt. This would facilitate a more direct evaluation of the predicted road dust loading (which is predicted by both of the used models) against measurements. 
Appendix A: Derivation of the conversion equation between the emission factor for all traffic and that for a van

The suspension emission factor of all traffic $\left(\mathrm{EF}_{\mathrm{tot}}\right)$ can be presented as the weighted sum of suspension emission factors of HDVs $\left(\mathrm{EF}_{\mathrm{hdv}}\right)$ and LDVs $\left(\mathrm{EF}_{\mathrm{ldv}}\right)$,

$\mathrm{EF}_{\mathrm{tot}}=$ frac $_{\mathrm{ldv}} \mathrm{EF}_{\mathrm{ldv}}+$ frac $_{\mathrm{hdv}} \mathrm{EF}_{\mathrm{hdv}}$,

where frachdv and frac ${ }_{\text {ddv }}$ are the fractions of HDVs and LDVs of the total traffic. The ratio of suspension emission factor for HDVs and LDVs is denoted as $r_{\mathrm{hdv}}$. Expanding the emission factor for LDVs in terms of the passenger cars $\left(\mathrm{EF}_{\mathrm{pCar}}\right)$ and vans $\left(\mathrm{EF}_{\mathrm{van}}\right)$, and using the above-mentioned ratio results in

$$
\begin{aligned}
& \mathrm{EF}_{\text {tot }}=\operatorname{frac}_{\text {ldv }}\left(f_{\mathrm{pCar}} \mathrm{EF}_{\mathrm{pCar}}+f_{\mathrm{van}} \mathrm{EF}_{\mathrm{van}}\right) \\
& +\operatorname{frac}_{\mathrm{hdv}} r_{\mathrm{hdv}}\left(f_{\mathrm{pCar}} \mathrm{EF}_{\mathrm{pCar}}+f_{\mathrm{van}} \mathrm{EF}_{\mathrm{van}}\right),
\end{aligned}
$$

where $f_{\mathrm{van}}$ and $f_{\mathrm{pCar}}$ are the fractions of vans and passenger cars of the LDVs. The ratio of suspension emission factor of passenger cars to those of vans is denoted by $r_{\mathrm{p} C a r}$. The suspension emission factor for a van $\left(\mathrm{EF}_{\mathrm{van}}\right)$ is thus

$$
\mathrm{EF}_{\mathrm{van}}=\frac{\mathrm{EF}_{\mathrm{tot}}}{\left(f_{\mathrm{pCar}} r_{\mathrm{pCar}}+f_{\mathrm{van}}\right)\left(\mathrm{frac}_{\mathrm{ldv}}+\text { frac }_{\mathrm{hdv}} r_{\mathrm{hdv}}\right)} .
$$


Acknowledgements. This study has been part of the Nordic Council of Ministers funded project NORTRIP (NOn-exhaust Road Traffic Induced Particle emissions - Development of tools for assessing the effect on air quality and exposure). We also gratefully acknowledge for the funding of the following projects: European Community LIFE+ REDUST project (EU Life09 ENV/FI/000579), the EC funded TRANSPHORM (Transport related Air Pollution and Health impacts - Integrated Methodologies for Assessing Particulate Matter) and APTA (The Influence of Air Pollution, Pollen and Ambient Temperature on Asthma and Allergies in Changing Climate) financed by the Academy of Finland.

Edited by: V.-M. Kerminen

\section{References}

Abu-Allaban, M., Gillies, J. A., Gertler, A. W., Clayton, R., and Proffitt, D.: Tailpipe, resuspended road dust, and brake-wear emission factors from on-road vehicles, Atmos. Environ., 37, 5283-5293, 2003.

Berger, J. and Denby, B.: A generalised model for traffic induced road dust emissions. Model description and evaluation, Atmos. Environ., 45, 3692-3703, 2011.

Bukowiecki, N., Lienemann, P., Hill, M., Furger, M., Richard, A., Amato, F., Prévôt, A. S. H., Baltensperger, U., Buchmann, B., and Gehrig, R.: $\mathrm{PM}_{10}$ emission factors for non-exhaust particles generated by road traffic in an urban street canyon and along a freeway in Switzerland, Atmos. Environ., 44, 2330-2340, 2010.

Boulter, P. G.: A review of emission factors and models for road vehicle non-exhaust particulate matter, Wokingham, UK, TRL Limited, TRL Report PPR065, available at: http://uk-air.defra.gov.uk/reports/cat15/0706061624_Report1_

_Review_of_Emission_Factors.PDF (last access: 13 December 2010), 2005.

Denby, B. R. and Sundvor, I. (in collaboration with: Johansson, C., Kauhaniemi, M., Härkönen, J., Kukkonen, J., Karppinen, A., Kangas, L., Omstedt, G., Ketzel, M., Pirjola, L., Norman, M., Gustafsson, M., Blomqvist, G., Bennet, C., Kupiainen, K., and Karvosenoja, N.): NORTRIP model development and documentation: NOn-exhaust Road TRaffic Induced Particle emission modelling, Norwegian Institute for Air Research, NILU OR 23/2012, available at: http://www.nilu.no (last access: 3 January 2013), 2012.

Denby, B. R., Sundvor, I., Johansson, C., Pirjola, L., Ketzel, M., Norman, M., Kupiainen, K., Gustafsson, M., Blomqvist, G., and Omstedt, G.: A coupled road dust and surface moisture model to predict non-exhaust road traffic induced particle emissions (NORTRIP), Part 1: road dust loading and suspension modelling, Atmos. Environ., 77, 283-300, doi:10.1016/j.atmosenv.2013.04.069, 2013a.

Denby, B. R., Sundvor, I., Johansson, C., Pirjola, L., Ketzel, M., Norman, M., Kupiainen, K., Gustafsson, M., Blomqvist, G., Kauhaniemi, M., and Omstedt, G.: A coupled road dust and surface moisture model to predict non-exhaust road traffic induced particle emissions (NORTRIP). Part 2: surface moisture and salt impact modelling, Atmos. Environ., 81, 485-503, 2013b.

Düring, I., Bächlin, W., Bösinger, R., Müller, W. J., and Lohmeyer, A.: Experiences when modelling roadside $\mathrm{PM}_{10}$ concentrations, in: Proceedings 9th Int. Conf. on Harmonisation within
Atmospheric Dispersion Modelling for Regulatory Purposes, Garmisch-Partenkirchen, Germany, 1-4 June 2004, 208-212, 2004.

Etyemezian, V., Kuhns, H., Gillies, J., Green, M., Pitchford, M., and Watson, J.: Vehicle-based road dust emission measurement: I - methods and calibration, Atmos. Environ., 37, 4559-4571, 2003a.

Etyemezian, V., Kuhns, H., Chow, J., Gillies, J., Green, M., Hendrickson, K., McGown, M., and Pitchford, M.: Vehicle-based road dust emission measurement (III): effect of speed, traffic volume, location, and season on $\mathrm{PM}_{10}$ road dust emissions in the Treasure Valley, ID, Atmos. Environ., 37, 4583-4593, 2003b.

Fitz, D. R., Bumiller, K., Etyemezian, V., Kuhns, H., and Nikolich, G.: Measurement of $\mathrm{PM}_{10}$ Emission Rates from Roadways in Las Vegas, Nevada Using a SCAMPER Mobile Platform with Real-Time Sensors, presented at the 14th International Emission Inventory Conference, 12-14 April 2005, Las Vegas, NV, USA, 13 pp., 2005.

Gertler, A., Kuhns, H., Abu-Allaban, M., Damm, C., Gillies, J., Etyemezian, V., Clayton, R., and Proffitt, D.: A case study of the impact of winter road sand/salt and street sweeping on road dust re-entrainment, Atmos. Environ., 40, 5976-5985, 2006.

Hussein, T., Johansson, C., Karlsson, H., and Hansson, H.-C.: Factors affecting non-tailpipe aerosol particle emissions from paved roads: on-road measurements in Stockholm, Sweden, Atmos. Environ., 42, 688-702, 2008.

Jacobson, T. and Wågberg, L. G.: Developing and upgrading of a prediction model of wear caused by studded tyres and an overview of the knowledge of the factors influencing the wear - Version 3.2.03, Linköping, The Swedish National Road and Transport Research Institute, VTI notat 7-2007, available at: http://www.vti.se/en/publications/pdf/developing-andupgrading-of-a-prediction-model-of-wear-caused-by-studded -tyres-and-an-overview-of-the-knowledge-of-the-factorsinfluencing-the-wear-version-3203.pdf (last access: 14 February 2014), 2007 (in Swedish, summary in English).

Johansson, C., Denby, B. R., Sundvor, I., Kauhaniemi, M., Härkönen, J., Kukkonen, J., Karppinen, A., Kangas, L., Omstedt, G., Ketzel, M., Massling, A., Pirjola, L., Norman, M., Gustafsson, M., Blomqvist, G., Bennet, C., Kupiainen, K., and Karvosenoja, N.: NORTRIP: NOn-exhaust Road TRaffic Induced Particle emissions, development of a model for assessing the effect on air quality and exposure, ITM-report 212, Department of Applied Environmental Science, Stockholm University, Stockholm, 2012.

Kauhaniemi, M., Kukkonen, J. Härkönen, J., Nikmo, J., Kangas, L., Omstedt, G., Ketzel, M., Kousa, A., Haakana, M., and Karppinen, A.: Evaluation of a road dust suspension model for predicting the concentrations of $\mathrm{PM}_{10}$ in a street canyon, Atmos. Environ., 45, 3646-3654, 2011.

Keskinen, J., Pietarinen, K., and Lehtimäki, M.: Electrical low pressure impactor, J. Aerosol Sci., 23, 353-360, 1992.

Keuken, M. P. (Ed.): Assessment of Non-exhaust PM by Road Traffic in Urban Areas, Air4EU-D7.1.2: Case study report, November, 20 pp., available at: http://www.air4eu.nl/PDF/Air4EU\% 20-\%20CS\%20D7.1.2.pdf (last access: 13 February 2014), 2006.

Kuhns, H., Etyemezian, V., Landwehr, D., MacDougall, C., Pitchford, M., and Green, M.: Testing Re-entrained Aerosol Kinetic 
Emissions from Roads (TRAKER): a new approach to infer silt loading on roadways, Atmos. Environ., 35, 2815-2825, 2001.

Kukkonen, J., Salmi, T., Saari, H., Konttinen, M., and Kartastenpää, R.: Review of urban air quality in Finland, Boreal Environ. Res., 4, 55-65, 1999.

Kukkonen, J., Konttinen, M., Bremer, P., Salmi, T., and Saari, H.: The seasonal variation of urban air quality in Northern European conditions, Int. J. Environ. Pollut., 14, 480-487, 2000.

Kupiainen, K.: Road dust from pavement wear and traction sanding, Monographs of the Boreal Environment Research, 26, Finnish Environment Institute, Helsinki, 52 pp., 2007.

Kupiainen, K., Pirjola, L., Viinanen, J., Stojiljkovic, A., and Malinen, A.: Street dust emission and prevention. Final Report of KAPU-project, City of Helsinki Environment Centre 13/2009, Helsinki, 102 pp., 2009 (in Finnish, summary in English).

Kupiainen, K. and Pirjola, L.: Vehicle non-exhaust emissions from the tyre-road interface - effect of stud properties, traction sanding and resuspension. Atmos. Environ., 45, 4141-4146, 2011.

Langston, R., Merle Jr., R. S., Etyemezian, V., Kuhns, H., Gillies, J., Zhu, D., Fitz, D., Bumiller, K., James, D. E., and Teng, H.: Clark County (Nevada) Paved Road Dust Emission Studies in Support of Mobile Monitoring Technologies, Clark County Department of Air Quality and Environmental Management, Desert Research Institute, University of California, Riverside, University of Nevada, Las Vegas, 22 December 2008, available at: http://www. epa.gov/ttn/chief/ap42/ch13/related/Final_Test_Report.pdf (last access: 15 February 2013), 2008.

MML: Land scanning data, file service of open data, National Land Survey of Finland, available at: http://www.maanmittauslaitos.fi/ en/opendata/acquisition (last access: 7 November 2012), 2012.

Omstedt, G., Bringfelt, B., and Johansson, C.: A model for vehicleinduced non-tailpipe emissions of particles along Swedish roads, Atmos. Environ., 39, 6088-6097, 2005.

Omstedt, G., Andersson, S., Gidhagen, L., and Robertson, L.: New model tools for meeting the targets of the EU Air Quality Directive: description, validation and evaluation of local air quality improvement due to reduction of studded tyre use on Swedish roads, Int. J. Environ. Pollut., 47, 79-96, 2011.

Pirjola, L., Parviainen, H., Hussein, T., Valli, A., Hämeri, K., Aalto, P., Virtanen, A., Keskinen, J., Pakkanen, T., Mäkelä, T., and Hillamo, R.: "Sniffer" - a novel tool for chasing vehicles and measuring traffic pollutants, Atmos. Environ., 38, 3625-3635, 2004.

Pirjola, L., Paasonen, P., Pfeiffer, D., Hussein, T., Hämeri, K., Koskentalo, T., Virtanen, A., Rönkkö, T., Keskinen, J., Pakkanen, T. A., and Hillamo, R. E.: Dispersion of particles and trace gases nearby a city highway: mobile laboratory measurements in Finland, Atmos. Environ., 40, 867-879, 2006.
Pirjola, L., Kupiainen, K. J., Perhoniemi, P., Tervahattu, H., and Vesala, H.: Non-exhaust emission measurement system of the mobile laboratory SNIFFER, Atmos. Environ., 43, 4703-4713, 2009.

Pirjola, L., Johansson, C., Kupiainen, K., Stojiljkovic, A., Karlsson, H., and Hussein, T.: Road dust emissions from paved roads measured using different mobile systems, J. Air Waste Manage., 60, 1422-1433, doi:10.3155/1047-3289.60.12.1422, 2010.

Pirjola, L., Kupiainen, K. J., Ritola, R., Malinen, A., Niemi, J., Julkunen, A., and Virtanen, T.: Non-exhaust $\mathrm{PM}_{10}$ emission factors, Proceedings of Abstracts for the 8th International Conference on Air Quality - Science and Application, 19-23 March 2012, Athens, Greece, p. 249, 2012.

Snilsberg, B., Myran, T., and Uthus, N.,: The influence of driving speed and tires on road dust properties, in: Snilsberg, B.: Pavement wear and airborne dust pollution in Norway. Characterization of the physical and chemical properties of dust particles, Doctoral Thesis, Trondheim, Norwegian University of Science and Technology, Doctoral theses at NTNU, 133 pp., 2008.

Tele Atlas NV: Mapinfo, StreetPro, Pitney Bowes Software Limited, United Kingdom, 2012.

US-EPA: Emission Factor Documentation for AP-42, Sect. 13.2.1, Paved Roads, Measurement Policy Group, Office of Air Quality Planning and Standards, US Environmental Protection Agency, available at: http://www.epa.gov/ttn/chief/ap42/ch13/ bgdocs/b13s0201.pdf (last access: 22 February 2013), 2011.

Venkatram, A.: A critique of empirical emission factor models: a case study of the AP-42 model for estimating $\mathrm{PM}_{10}$ emissions from paved roads, Atmos. Environ., 34, 1-11, 2000.

WHO: WHO air quality guidelines global update 2005, Report on a working group meeting, 18-20 October, World Health Organization, Bonn, Germany, 2005.

Wood, C. R., Järvi, L., Kouznetsov, R. D., Nordbo, A., Joffre, S., Drebs, A., Vihma, T., Hirsikko, A., Suomi, I., Fortelius, C., O'Connor, E. J., Moisseev, D., Haapanala, S., Moilanen, J., Kangas, M., Karppinen, A., Vesala, T., and Kukkonen, J.: An overview on the Urban Boundary-layer Atmosphere Network in Helsinki, B. Am. Meteorol. Soc., 94, 1675-1690, doi:10.1175/BAMS-D-12-00146.1, 2013. 